\title{
DIÁLOGOS DRAMATÚRGICOS E O MITO DE PIGMALIÃO NA PEÇA O COLETE DE XADREZ, DE PRISTA MONTEIRO
}

\author{
DRAMATURGICAL DIALOGUES AND THE MYTH OF PYGMALION IN \\ THE PLAY O COLETE DE XADREZ, BY PRISTA MONTEIRO
}

\author{
Márcia Regina Rodrigues \\ UNESP - Araraquara
}

\begin{abstract}
RESUMO: As peças de Helder Prista Monteiro (1922-1994) - considerado pela crítica um dos representantes do teatro do absurdo produzido em Portugal - apresentam um claro diálogo com as obras dramáticas de Samuel Beckett e Eugène lonesco e tratam, em geral, da fragilidade ou do desmoronamento das relações intersubjetivas. Em $O$ colete de xadrez, Prista Monteiro dialoga não só com a obra dos dramaturgos do teatro do absurdo, mas, em certa medida, com as peças Escola de Mulheres, de Molière, e Pigmalião, de Bernard Shaw, ao abordar também, ainda que numa perspectiva absurdista, o mito de Pigmalião, narrado por Ovídio em Metamorfoses.

Este texto tem como objetivo mostrar como o autor português estabelece esses diálogos dramatúrgicos e discutir o tratamento que a peça $O$ colete de xadrez confere ao mito de Pigmalião, considerando os pressupostos do teatro do absurdo apontados por Martin Esslin e as reflexões de Mircea Eliade sobre os comportamentos míticos na sociedade moderna.
\end{abstract}

PALAVRAS-CHAVE: Teatro e mito; Teatro do absurdo; Prista Monteiro; Diálogos dramatúrgicos

ABSTRACT: The plays of Helder Prista Monteiro (1922-1994) - considered by critics one of the exponents of the theatre of the absurd in Portugal - present a clear dialogue with the dramatic works of Samuel Beckett and Eugène lonesco. In general the plays deal with the frailty and tumbling of the intersubjective relationships.

In the play O colete de xadrez [The check vest], Prista Monteiro dialogues not only with the work of the dramaturgs of the theatre of the absurd, but, to some extent, with Molière's play The School for Wives and Bernard Shaw's Pygmalion as well, since it approaches the myth of Pygmalion as told by Ovídio in Metamorphoses, even if from a absurdist perspective.

This article intends to show how the Portuguese author sets these dramaturgical dialogues. It discusses how the play $\mathrm{O}$ colete de xadrez [The check vest] addresses the myth of Pygmalion, based both on the assumptions of the theatre of the absurd, as stressed by Martin Esslin, and on the considerations put forward by Mircea Eliade about mythical behavior in modern society.

KEYWORDS: Theatre of the Absurd; Theatre and myth; Dramaturgical dialogues; Prista Monteiro; Portuguese theatre. 


\section{Revista do SELL}

v. $4, n^{\circ} .2$

ISSN: $1983-3873$

\section{Introdução}

Um mundo que se pode explicar, mesmo com raciocínio errôneo, é um mundo familiar. Mas num universo repentinamente privado de ilusões e de luzes, pelo contrário, o homem se sente estrangeiro. (...) Esse divórcio entre o homem e sua vida, o ator e seu cenário é precisamente o sentimento do absurdo.

(CAMUS, 2004, p. 20)

Ao longo de sua carreira, Helder Prista Monteiro (1922-1994) ${ }^{1}$ - considerado pela crítica um dos representantes do teatro do absurdo em Portugal e que obteve autorização da censura salazarista para a encenação de suas primeiras peças durante a ditadura ${ }^{2}$ buscou inspiração em um universo dramatúrgico bastante conhecido, estabelecendo um franco e claro diálogo com os dramaturgos de seu tempo, especialmente com a obra de Samuel Beckett e a de Eugène Ionesco.

As peças pristamonteirianas também dialogam umas com as outras ${ }^{3}$, principalmente no que se refere à construção das dramatis personae, as quais constituem um universo povoado por figuras muito parecidas, revelando uma dramaturgia tecida por variações do mesmo tema: as frustrações individuais e as relações pessoais no seio da família burguesa, esta preocupada apenas com o que se passa entre quatro paredes. Geralmente as peças de Prista Monteiro apresentam uma figura que introduz se não a ilogicidade total pelo menos a falta de sentido parcial ou ainda uma lógica particular incompreensível para as demais personagens, comprometendo as relações pessoais.

Nesse quadro dramatúrgico, o autor se utiliza de expedientes que se repetem ou serão retomados em obras posteriores de sua produção, fazendo evoluir ou regredir certas características comuns de personagens que se assemelham, muitas delas aprisionadas em seu próprio habitat - casas, quartos, sala familiar - incapazes de interação com seus pares.

\footnotetext{
${ }^{1}$ Helder Prista Monteiro (1922-1994) era médico de formação e a essa carreira se dedicou ao longo de sua vida, mantendo paralelamente a atividade de dramaturgo a partir de 1959 - ano da escrita de sua primeira peça, Os imortais. Ele publicou ao todo dezessete peças entre 1968 e 1993, sendo principalmente as do início de sua produção dramatúrgica as que mais tornaram a sua obra associada ao teatro do absurdo. O dramaturgo ficou um pouco conhecido fora de Portugal ao ter duas de suas peças adaptadas para o cinema pelo grande realizador português Manoel de Oliveira: A caixa, filme homônimo de 1994, e Os imortais, peça adaptada no filme Inquietude, de 1998.

${ }^{2}$ É preciso aqui lembrar que nos quarenta e oito anos da ditadura portuguesa, o teatro esteve sempre sob a mira da censura que proibiu a encenação de peças de autores portugueses e estrangeiros.

${ }^{3}$ Característica que talvez explique o fato de Luzia Maria Martins ter montado no mesmo espetáculo três obras do dramaturgo em 1966 - A rabeca, O meio da ponte e $O$ anfiteatro - e, em 1983, Manuel Coelho ter levado à cena em Lisboa, no Teatro D. Maria II, Reis coxos, espetáculo realizado a partir de uma coletânea de textos de Prista Monteiro.
} 


\section{Revista do SELL \\ v. $4, n^{\circ} .2$ \\ ISSN: $1983-3873$}

Assim, ao repetirem situações parecidas, nas quais são recorrentes personagens que apresentam atitudes, gestos e comportamentos obsessivos, as peças de Prista Monteiro mostram a fragilidade ou o desmoronamento das relações intersubjetivas e a dificuldade do homem em lidar com a experiência de perceber a sua capacidade de ação frustrada pelas contingências da vida, pelo meio social, ou pela própria condição humana, aproximando a sua dramaturgia do teatro do absurdo.

$\mathrm{Na}$ peça que aqui tratamos, O colete de xadrez, escrita nos anos de 1960 e publicada vinte anos mais tarde, Prista Monteiro dialoga com os dramaturgos do teatro do absurdo e, em certa medida, com Molière e Bernard Shaw ao abordar também o mito de Pigmalião - narrado por Ovídio nas suas Metamorfoses. O protagonista, Jorge, um professor de francês, depois de dois casamentos desfeitos, toma a decisão de educar a sua aluna de onze anos para que ela adquira as virtudes que lhe interessam, a ele, como sua futura esposa (primeiro ato). Jorge deseja uma mulher que nunca mude, pois julga que ele próprio não sofre e nem sofrerá mudanças e, apesar de advertido pelo melhor amigo, leva adiante o seu plano. O segundo ato consiste na representação da passagem do tempo (sete anos), apresentando no palco sempre o último dia de férias quando a família de Teresa está aprontando as malas para ir embora, a mãe apaga as luzes, e voltam todos para a cena que representará o último dia de férias e assim sucessivamente. Neste tempo, Teresa torna-se mulher, cada vez mais submissa a Jorge e cada vez mais parecida com ele no modo de se vestir, ela usa um colete de xadrez igualzinho ao dele. $O$ colete será o símbolo de sua entrega a Jorge e ela passará o terceiro ato a costurar um novo colete, igual ao outro, sempre feliz e orgulhosa de sua costura, mas alienada do mundo.

O colete de xadrez dialoga com Escola de Mulheres (Molière) e com Pigmalião (Shaw), peças essencialmente cômicas; mas, por outro lado, acentua a relação tragicômica da situação apresentada - como faz, por exemplo, lonesco em $A$ lição, para citar um dramaturgo absurdista com o qual o dramaturgo português dialoga - e propõe "o desmascarar, e a demolição, do mito de Pigmalião", como bem apontou Sebastiana Fadda (1998, p. 293).

$\mathrm{Na}$ construção dramatúrgica de $\mathrm{O}$ colete de xadrez, Prista Monteiro define o comportamento do protagonista a partir do mito, isto é, Jorge deseja repetir o mito de Pigmalião numa tentativa de alcançar a tranquilidade conjugal, como faz o Arnolfo de Molière. A análise do comportamento mítico do protagonista leva a uma das designações de mito definidas por Mircea Eliade, qual seja, a de que a repetição do mito para o homem 


\section{Revista do SELL \\ v. $4, n^{\circ} .2$}

ISSN: $1983-3873$

moderno representa uma garantia de sucesso na sua realização pessoal. $O$ colete de xadrez, no entanto, inverte duplamente o mito na medida em que a metamorfose operada pelo protagonista converte a sua aluna, e depois esposa, simbolicamente em uma estátua e Jorge se vê ele próprio transformado diante do resultado alcançado e não mais desejado. Para Martin Esslin (1968, p. 348), uma das representações do teatro do absurdo é "a confrontação do homem com as esferas do mito e da realidade religiosa", de modo a tornar o ser consciente da sua posição precária no mundo.

Assim, apoiados nas reflexões de Mircea Eliade sobre comportamentos míticos na sociedade moderna e nos pressupostos do teatro do absurdo apontados por Martin Esslin, apresentamos a seguir considerações sobre o mito de Pigmalião; a forma pela qual $\mathrm{O}$ colete de xadrez dialoga com a peça de Molière e a de Bernard Shaw e o tratamento que Prista Monteiro confere ao mito.

\section{Il. O mito de Pigmalião em Metamorfoses}

\section{A face era a de uma jovem autêntica, a qual tu julgarias estar viva e que queria, não obstasse a timidez, mover-se. \\ A tal ponto a arte não se vê na arte! Pigmalião extasia-se \\ a olhá-la e sorve no peito chamas pelo corpo de imitação.}

(OVÍDIO, 2007, p. 252)

O mito de Pigmalião é narrado no Livro X das Metamorfoses, de Ovídio, e constitui uma das canções que entoa Orfeu depois de ter perdido Eurídice pela segunda vez, ao desobedecer aos deuses e olhar para trás em busca da sua amada ainda nos vales do Averno, o submundo das trevas.

Orfeu canta os "rapazes pelos deuses amados, bem como as raparigas, fulminadas por paixões proibidas, que foram castigadas pela sua lascívia" (OVÍDIO, 2007, p. 249), ou seja, narra histórias de infortúnio, de amor, algumas de amor proibido - como, por exemplo, a de Mirra que se apaixona pelo pai -, tendo a maior parte delas um desfecho trágico, resultando numa metamorfose dos mortais atribuída pelos deuses, em geral como castigo. É o que acontece aos Cerastas - convertidos em touros - e às Propétides transformadas em estátuas -, ambos castigados por Vênus; aqueles por terem profanado o templo de Júpiter e estas por terem ousado afirmar que a deusa não era verdadeiramente uma deusa: "Por isso, devido à cólera da deusa, diz-se que foram [as Propétides] as primeiras a prostituir o corpo e a beleza; e quando perderam o pudor e o sangue do rosto endureceu, com uma diferença mínima converteram-se em rígida pedra" 


\section{Revista do SELL}

v. $4, n^{\circ} .2$

ISSN: $1983-3873$

(OVÍDIO, 2007, p. 252); daí as prostitutas serem frequentemente associadas a estátuas, ou seja, frias e desprovidas de sentimentos. É este canto que servirá de deixa para o próximo, o mito de Pigmalião.

Inconformado com a inconstância da índole feminina, Pigmalião resolve ficar solteiro, contudo sofre imenso com a falta de alguém que the faça companhia e ocupe o seu leito, por isso ele esculpe em marfim uma linda e delicada mulher e tanto a admira e contempla que se vê apaixonado por ela. Timidamente Pigmalião pede aos deuses que Ihe concedam uma esposa semelhante àquela que ele moldou na pedra e Vênus entende o pedido e transforma a estátua em mulher de carne e osso:

Ao ser tacteado, o marfim torna-se mole! A rigidez esvai-se, e sob os dedos cede e molda-se, tal como a cera do Himeto sob o sol amolece e, moldada pelos dedos, cede a mudar-se em formas sem conta, tornando-se útil pelo próprio uso.

(...)

Era corpo humano! As veias tacteadas pelo polegar latejam! (OVÍDIO, 2007, p. 253)

No Livro X, apesar de a metamorfose constituir aos olhos de Vênus um tipo ideal de castigo - "Melhor seria que esse povo ímpio fosse punido com o exílio, ou com a morte, ou algo de intermédio entre o exílio e a morte. E que poderá ser isso senão o castigo de mudarem de forma?" (Ovídio, 2007, p. 251) -, nem sempre é por essa razão que a transformação se dá; assim como também não é regra que a metamorfose seja uma atribuição dos deuses aos homens, pois até Júpiter se metamorfoseia em águia para conquistar o belo e jovem Ganimedes, o descendente de Ilo. A Jacinto e Adónis, por exemplo, não Ihes é atribuída a metamorfose como castigo, ao contrário, os dois, depois de mortos acidentalmente, são transformados em flor ${ }^{4}$ pelos deuses, com o intuito de eternizar a memória dessas personagens.

O caso de Pigmalião difere de todos os outros narrados no Livro X. Pigmalião se casa com a donzela branca e da união nasce Pafo. Assim, a metamorfose neste caso não é resultado de castigo ou de infortúnio da personagem, ao contrário, é fruto da paixão do escultor que concretiza o seu desejo humano e carnal por meio da arte.

\footnotetext{
${ }^{4}$ Jacinto é morto acidentalmente quando tenta apanhar o disco arremessado por Febo. Inconformado com a morte de Jacinto, Febo transforma o sangue do jovem em flor. Adónis, por sua vez, mesmo sendo advertido por Vênus sobre o perigo das feras, é morto por um javali, para o desespero da deusa que, então, transforma-o em anêmona.
} 


\section{Revista do SELL}

v. $4, n^{\circ} .2$

ISSN: $1983-3873$

A metamorfose da estátua convertida em mulher também transforma Pigmalião, pois o escultor é elevado ao estatuto de um deus criador, capaz de soprar vida à sua criação, realização alcançada pela força do seu trabalho artístico e pelo seu forte desejo. Assim, Pigmalião dá forma artística à forma bruta, ou seja, ele parte de um objeto inanimado (pedra) para a vida, fazendo nascer Galatéia. Podemos dizer que ao realizar o seu desejo, Pigmalião - ao contrário das outras personagens das canções de Orfeu - é contemplado com a boa sorte a ele atribuída pela deusa Vênus em reconhecimento do talento artístico e da humildade do escultor que, diante dos deuses, nas suas preces, pede-lhes uma "esposa semelhante à de marfim" (OVÍDIO, 2007, p. 253).

Vemos basicamente dois tipos de metamorfoses nas narrações do Livro X: aquelas que constituem punições (Cerastas, transformados em touros; Propétides, em estátuas; Mirra, em árvore; Atalanta e Hipómenes, em leões) e aquelas que constituem uma espécie de ressarcimento, ou seja, reparação de um dano (Jacinto, convertido em flor; Adônis, em anêmona); as metamorfoses punitivas se dão em vida e as metamorfoses de ressarcimento ocorrem depois da morte das personagens, para que elas sejam lembradas eternamente. Duas metamorfoses não se encaixam nesses dois modelos, a de Júpiter em ave - "a que consegue carregar os raios" - e a da estátua esculpida por Pigmalião transformada em mulher. Mas Júpiter é um deus e se metamorfoseia a seu bel-prazer e de acordo com os seus interesses; no entanto, nos dois casos há uma semelhança, tanto os motivos de Júpiter ao se metamorfosear quanto os de Pigmalião são carnais. A partir da metamorfose, a figura de Pigmalião, personagem que alcança a realização do seu desejo, torna-se estatutária da de um deus, pois a sua criação ganha e gera a vida (ele e Galatéia concebem Pafo). Lembremos, no entanto, que não está aparente na personalidade dessa personagem mítica traços de soberba, o escultor não se acha um deus, apenas cria a imagem da mulher que julga ideal. O que impulsiona Pigmalião a criar a estátua feminina perfeita é a sua desilusão com as mulheres, mas o que impulsiona 0 seu desejo confesso de dar-Ihe vida é o fato de ter o seu leito vazio, ou seja, a vontade de aplacar a sua carência, a sua solidão. Apesar de os descendentes de Pigmalião sofrerem metamorfose como uma espécie de castigo (Mirra, sua neta, seduz o próprio pai, Ciniras, filho de Pafo, e ela própria pede aos deuses para ser castigada e eles a transformam em árvore) ou de ressarcimento (Adônis, amante de Vênus, filho da relação incestuosa de Mirra e Ciniras, é convertido em flor pela deusa), a metamorfose que deseja o escultor é atendida pelos deuses, sendo, pois, nem um castigo, nem um ressarcimento, mas uma dádiva merecida pela sua paixão ou ainda pelo seu engenho e arte. 


\section{Revista do SELL}

v. $4, n^{\circ} .2$

ISSN: $1983-3873$

As peças que aqui temos em vista: Escola de Mulheres, de Molière; Pigmalião, de Bernard Shaw e O colete de xadrez, de Helder Prista Monteiro, têm como base da fábula o mito de Pigmalião e apresentam protagonistas com um desejo em parte semelhante ao da personagem mítica, qual seja, o de moldar uma mulher; no entanto, cada autor dá um tratamento diferente ao mito, encaixando-o na chave da comédia, como faz Shaw e Molière - ainda que de formas distintas - ou numa perspectiva absurdista, como faz Prista Monteiro.

\section{Diálogos dramatúrgicos}

Arnolfo - (...) É um pedaço de cera em minhas mãos: darei a ela a forma que eu quiser.

(MOLIÈRE, 1980, p. 208)

Henrique - (...) A senhora não imagina como apaixona pegar um ser humano e transformá-lo aos poucos, através de uma nova linguagem, num ser completamente diverso do anterior!

(SHAW, 1964, p. 290)

Jorge - (...) Isto! Vou "fabricar" uma esposa! (...)

Outro colega (Trocista) - (...) Fabricar!? De quê? De barro, de madeira, de plástico? Para não dizer outra coisa?...

Jorge (Sério) - Da mesma matéria que as outras... mas com outra alma!

(PRISTA MONTEIRO, 1983, p. 38)

Arnolfo - protagonista da clássica comédia de Molière, Escola de Mulheres -, devido ao seu grande medo de ser traído por uma futura esposa, pretende se casar com aquela que educou desde os quatro anos de idade em total ignorância sobre as coisas da vida mundana. No diálogo com Crisaldo, Arnolfo explica detalhada e longamente as características que ele julga adequadas para a sua futura esposa:

Mulher que escreve sabe mais do que é preciso! Pretendo que a minha seja bastante opaca para não saber nem mesmo o que é uma rima. (...) Em suma, desejo uma mulher de extrema ignorância. Que já seja demais ela saber rezar, me amar, cozer, bordar!

(MOLIĖRE, 1980, p. 160).

Cego na sua prepotência, Arnolfo se aproveita da condição social inferior da camponesa pobre para atingir o seu objetivo, julgando ter poder total sobre ela e ainda ser ele merecedor de reconhecimento por transformá-la: 


\section{Revista do SELL}

v. $4, n^{\circ} .2$

ISSN: $1983-3873$

Vou me casar com você, Inês; cem vezes por dia você deverá agradecer esta honra bendita, lembrando a baixeza onde você nasceu, ao mesmo tempo que admira minha bondade, que a eleva dessa vil condição de camponesa pobre à dignidade burguesa, para partilhar do leito e dos abraços conjugais de um homem que mais de vinte vezes recusou a outras o coração e a honra que agora te oferece.

(MOLIẼRE, 1980, p. 203)

O trabalho de Arnolfo em tornar Inês ao longo de treze anos uma mulher casta e ignorante não resulta. Em pouco tempo a moça aprende muito com Horácio, seu amante, e imediatamente se dá conta do estado de ignorância em que vivia e se rebela contra o seu tutor, rejeitando-o como marido. Arnolfo se vê, então, ridicularizado pelos seus atos e duplamente castigado: pela sua presunção em querer moldar uma esposa, ingenuamente acreditando que ela não teria vontade própria, e de ver a sua pretendida casada com outro, tendo ele que, como um cachorrinho acuado, sair à francesa.

Se Arnolfo é um fracassado nos seus projetos, o mesmo não acontece com Henrique (Henry Higgins) ${ }^{5}$, de Pigmalião, peça de Bernard Shaw, que mostra, no decorrer dos cinco atos, a transformação da florista Elisa em dama da sociedade, objetivo idealizado e alcançado pelo professor, que, por meio de suas aulas de fonética e de boas maneiras, opera a transformação na moça pobre e ignorante. Mas Shaw cria um Pigmalião que, apesar de orgulhoso de sua "obra-prima", não se interessa em se casar com a mulher que moldou, pois o professor afirma ser um celibatário empedernido:

HENRIQUE - As mulheres estragam tudo. Quando consentimos que entrem em nossa vida, descobrimos que a mulher busca uma coisa, e nós outra coisa diferente (...) Um quer ir para o norte, outro para o sul: o resultado é que os dois são obrigados a ir para o leste, detestando cordialmente o vento que os leva para lá... (...) É por isso que sou um solteirão inveterado, e que assim espero morrer!

(SHAW, 1964, p. 257)

Em Pigmalião, o risível da comédia está nas dificuldades da florista em atingir o objetivo do professor Henrique e em Escola de Mulheres está na altivez e na previsível falha de Arnolfo na tentativa de realizar o seu desejo. Ainda que com intenções diferentes, Arnolfo e Henrique são "escultores" prepotentes que se aproveitam da condição social da

\footnotetext{
${ }^{5} \mathrm{Na}$ tradução para o português da peça de Bernard Shaw, Miroel Silveira adapta os nomes das personagens; assim Henry Higgins passa a ser Henrique Mascarenhas e Eliza Doolitlle do original a Elisa Garapa na adaptação.
} 


\section{Revista do SELL}

v. $4, n^{\circ} .2$

ISSN: $1983-3873$

moça pobre que resolveram educar; a diferença é que o protagonista de Molière não atinge o seu objetivo e é castigado por sua presunção e o de Shaw alcança seu propósito, tal como a personagem mítica, daí o título da peça de Shaw ser Pigmalião.

Já na peça $O$ colete de xadrez, de Prista Monteiro, o protagonista Jorge apresenta características de Arnolfo e de Henrique e o mesmo impulso da personagem mítica, pois, como para Pigmalião, não Ihe agrada as características da personalidade feminina, por isso quer esculpir, ou fabricar, uma esposa:

JORGE - (...) As mulheres não querem senso. Odeiam-no! Em regra não o têm. Substituíram-no por instinto e detestam viver lado a lado com um homem que tenha sempre razão (...).

(...)

AMIGO - Mas ouve, Jorge! Isso tudo é ingênuo. Percebes? Uma mulher, uma esposa, não se fabrica! Não é um objeto!

JORGE - Nisso é que tu te enganas. (...)

(PRISTA MONTEIRO, 1983, p. 42-43)

A opinião de Jorge sobre as mulheres se aproxima da de Henrique - e, como no Pigmalião de Shaw, Jorge é professor e Teresa sua aluna - porém o protagonista de $O$ colete de Xadrez deseja uma esposa que não mude com o passar do tempo, como ocorreu com as outras que já teve, e tal tarefa leva anos (Arnolfo leva treze anos e Jorge sete). Nas aulas, em casa da família de Teresa, sempre nas férias de verão, fica clara a força autoritária do professor - "Faça o que eu Ihe mandar!", diz ele a Teresa - e o seu posicionamento de superioridade em relação à mulher, como podemos inferir pelo conteúdo dos textos que ele "manda" a menina traduzir do francês:

TERESA - Bom!... "Serei a tua escrava e tu... serás o meu senhor. Tu... mandarás... eu obedecerei" não "e eu obedecerei, como... fidele... fiel!?" Ora! Não percebo! O senhor professor sabe? Quem está a falar é a mulher do rei... ou do chefe. Mas parece esquisito! É como se ela estivesse a pedir para ser a criada do marido!... Mas é ela que está a pedir! $(\ldots)$

JORGE - Sim! Daqui a mais algum tempo a Teresa perceberá! Agora vamos lá andando.

(PRISTA MONTEIRO, 1983, p. 52)

Ao longo dos anos, Jorge vai tirando a vida da menina; ela cresce e se torna uma mulher sem vida própria. É como se ela fosse assumindo as características do marido, 


\section{Revista do SELL}

v. $4, n^{\circ} .2$

ISSN: $1983-3873$

mas sem conseguir camuflar aquilo que the é do interior, pois perde o senso crítico, deixando, assim, transparecer o que há de mais contraditório na personalidade do esposo. Teresa é o duplo de Jorge, o seu espelho, que deixa refletir, sem que tenha consciência disso, o mais contraditório da personalidade do marido, que ele tenta em vão esconder. Desse modo, Jorge molda uma mulher que se transforma em seu espelho invertido e é isso que ele não suporta. No terceiro ato, Jorge e Teresa estão casados já há alguns anos e ela se tornou uma mulher obcecada pelas preferências do marido: coleciona todas as versões da música que ele gosta - "Folhas Mortas" - e se ocupa em confeccionar e vestir coletes de xadrez iguais aos que ele usava quando era o professor dela. Como Teresa não muda, suas ações são repetitivas, mecanizadas, deflagrando um cotidiano maçante e insuportável para Jorge que finalmente constata ter criado não uma mulher, mas uma boneca e como tal sem vida, apesar de animada.

Diferentemente das comédias de Molière e Bernard Shaw, em que as ações das personagens apresentam causa e consequência, $O$ colete de xadrez cena a cena aponta para o absurdo das situações apresentadas, principalmente no terceiro ato, dia do aniversário de Jorge, que recebe os amigos. Quando Teresa comparece em cena, a coser e a experimentar coletes de xadrez, dispara frases que ela deve ter ouvido quando era aluna de Jorge: "(Feliz como quem recita uma lição aprendida de cor): 'Há rapazes a quem a dor física chama a cumprir as suas obrigações"” ou "Até os bichos aprendem... com uma ou duas chibatadas" (PRISTA MONTEIRO, 1983, p. 105-106). comportamento de Teresa denuncia uma mulher presa a sua condição do passado, isto é, de aluna frente ao seu professor, a repetir a lição decorada sem nenhuma reflexão, como um robô. Na maioridade, Teresa troca de posição - de aluna passa a esposa -, mas não muda de comportamento, espelhando, com isso, o autoritarismo que Jorge usou para educar a moça e que ele agora procura esconder dos colegas professores que recriminam o abuso de poder e violência na escola onde trabalham. É que Jorge reconhece que mudou e que não é mais um professor autoritário: "Odeio a violência, os cinturões e... e... e as botas de cano alto!..." (PRISTA MONTEIRO, 1983, p. 110). A constatação e afirmação da mudança são enfatizadas nas últimas falas da peça, articuladas pela repetição das palavras, como que procurando ecoar o desespero do protagonista que se vê só: 


\section{Revista do SELL}

v. $4, n^{\circ} .2$

ISSN: $1983-3873$

Mu-dei-sozinho!

So-zinho! So-zinho! So-zinho!So-zinho!

(PRISTA MONTEIRO, 1983, p. 111)

Neste mesmo terceiro ato, Jorge agora mudado faz outra constatação: "Moldaste uma estátua", diz ele ao 1ํㅡorge - uma espécie de fantasma de si próprio, que ainda usa colete de xadrez e laço -, que mais adiante lhe responde: "Ela devolveu-te tudo, tudo... intacto, imutável... Recebeu, mas não aceitou..." (PRISTA MONTEIRO, 1983, p. 93-94).

Se no mito de Pigmalião a rigidez da mulher esvai-se e a personagem mítica, através do seu trabalho artístico, realiza o seu desejo, o de aplacar a solidão, em $O$ colete de xadrez ocorre exatamente o contrário, pois Teresa dos com o passar dos anos transforma-se em uma estátua e Jorge se vê completamente abandonado na solidão. Assim, como é comum nas peças de Prista Monteiro, temos mais uma personagem que se descobre solitária no mundo: "Pelo caminho, ou pelo atalho, não encontramos ninguém!..." (PRISTA MONTEIRO, 1983, p. 113). Ao final, calmo e tranquilo Jorge dá cabo da própria vida - e isso se mostra numa cena antinaturalista, porque do revólver que Jorge encosta à cabeça não se ouve nenhum tiro, mas ele cai morto.

Como em Molière e em Shaw, o protagonista de Prista Monteiro tem a essência da personagem do mito de Pigmalião, qual seja, a do escultor que intencionalmente molda a figura feminina; no entanto, em Shaw a metamorfose resulta de certa forma positiva, pois a florista Elisa consegue passar por uma dama da sociedade, como queria o professor Henrique; em Molière, a transformação pretendida por Arnolfo converte-se em castigo para o "criador", já que o tutor de Inês não apenas sofre traição como não se casa com a moça e em Prista Monteiro há uma inversão do mito como referimos há pouco e, diferentemente de um castigo, a transformação ou metamorfose do sujeito em que se pôs a mira (a esposa) atinge e modifica o próprio sujeito que a desejou (o marido). Jorge desejava uma mulher que não mudasse, e de certa forma conseguiu (como Henrique consegue a transformação desejada), mas não contava que ele próprio mudaria.

A repetição do mito como última tentativa do sujeito de alcançar a tranquilidade mostra-se falha. Não é porque não consegue atingir o seu objetivo que Jorge se suicida, mas é por constatar que não é capaz de suportar aquilo que um dia desejou; trata-se, pois, da nítida constatação da contradição humana que, por sua vez, revela a condição absurda do ser. Assim, como afirma Camus (2004, p. 66), "à sua maneira o suicídio resolve o absurdo". 


\title{
Revista do SELL
}

v. $4, n^{\circ} .2$

ISSN: $1983-3873$

\section{Considerações finais}

\begin{abstract}
A dessacralização ininterrupta do homem moderno alterou o conteúdo da sua vida espiritual, mas não quebrou as matrizes da sua imaginação: todo um resíduo mitológico sobrevive nas zonas mal controladas.
\end{abstract}

(ELIADE, 1979, p. 14)

Para o protagonista de $O$ colete de xadrez ter uma esposa que possa reconhecer que ele tem sempre razão é a chave do sucesso do casamento e a conquista da tranquilidade conjugal, por isso ele recorre ao comportamento mítico: "Pode-se 'fabricar' uma esposa. Olha, a história antiga está cheia disso. E não se conheciam divórcios" (PRISTA MONTEIRO, 1983, p. 43), diz ele ao amigo, afirmação semelhante, aliás, à que aparece no "Epílogo" de Pigmalião: "E a história de Elisa, qualificada embora como ficção, por narrar uma transformação aparentemente improvável, é bastante comum" (SHAW, 1964, p. 333).

Nas entrelinhas, Prista Monteiro leva a personagem de sua peça a uma acepção do mito muito próxima daquela descrita por Mircea Eliade (1972, p. 101, grifo do autor): "o mito garante ao homem que o que ele prepara para fazer já foi feito; e ajuda-o a eliminar as dúvidas que poderia conceber quanto ao resultado de seu empreendimento"; porém, a fórmula que Jorge busca na esfera mítica para a sua criação (repetir o mito de Pigmalião) coloca-o, para o seu espanto e terror, frente a frente com a sua própria contradição e o aprisiona na solidão: "Preciso conviver, viver... discutir... Preciso... misturar-me com os outros! Porque não compreende ela isto?" (PRISTA MONTEIRO, 1983, p. 97).

De acordo com Mircea Eliade (1972, p. 127), alguns comportamentos míticos sobrevivem no mundo moderno "não que se trate de sobrevivências de uma mentalidade arcaica. Mas alguns aspectos e funções do pensamento mítico são constituintes do ser humano" e uma das funções do mito apontadas pelo historiador das religiões é "revelar modelos e fornecer, assim, uma justificação do Mundo e da existência humana" (ELIADE, 1972, p. 103), por isso o universo do mito também se manifesta nas aspirações do homem moderno.

Martin Esslin (1968, p. 298) - crítico inglês que cunhou o termo teatro do absurdo ao analisar peças de Beckett, Ionesco, Genet, Adamov e outros -, apoia-se nesta afirmação de Eliade para explicar que "o uso de modos míticos, alegóricos e sonhadores de pensamento, ou seja, projeções concretas de realidades psicológicas" aparecem no teatro do absurdo por meio de situações, de imagens, e denunciam as formas 


\section{Revista do SELL}

v. $4, n^{\circ} .2$

ISSN: $1983-3873$

"inautênticas" de viver, focalizando o absurdo da condição humana. Mas, se para Eliade (1972, p. 132), "comportamentos míticos poderiam ser reconhecidos na obsessão do 'sucesso', tão característica da sociedade moderna, e que traduz o desejo obscuro de transcender os limites da condição humana"; no caso do teatro do absurdo, as personagens se deparam com a impossibilidade da transcendência dos limites humanos e, então, reconhecem frustradas o absurdo da própria condição. O reconhecimento do absurdo da condição humana, segundo Esslin (1968), dá-se logo após o término da Segunda Guerra quando o homem se viu abandonado, completamente perdido em um mundo onde as suas certezas se dissipavam e a vida tornava-se sem sentido. Oteatro do absurdo representa o reflexo dessa época de abalo das certezas absolutas e tem por objetivo tornar o seu público consciente da posição do homem no mundo; por isso se preocupa em mostrar a situação básica do indivíduo (ESSLIN, 1968)..

Antes de seu encontro com o absurdo, o homem cotidiano tinha a ilusão de ser livre; "depois do absurdo tudo fica abalado", escreve Albert Camus (2004, p. 68), pois tudo "acaba sendo desmentido de maneira vertiginosa pelo absurdo de uma morte possível", de modo que fica difícil ao homem crer num amanhã. Quanto a isso não há "nada a fazer", frase que se repete na boca dos vagabundos de Beckett ou como cita a Professora Nova, personagem de $O$ colete de xadrez: "Ficará sempre algo por que o homem dirá: 'nada a fazer'!' (PRISTA MONTEIRO, 1983, p. 100), expressão que enfatiza nessas peças certo pessimismo ou negativismo - como apontou Célia Berrenttini (2004) na análise do termo nada em Esperando Godot ${ }^{6}$.

Quanto ao diálogo que a peça de Prista Monteiro estabelece com aquelas que também apresentam na base da fábula o mito de Pigmalião lembramos que tanto Pigmalião, de Shaw, quanto Escola de Mulheres, de Molière, inserem-se na chave da comédia e $O$ colete de xadrez, por meio de uma construção dramatúrgica em que apresenta situações e imagens que se repetem, permeadas em dados momentos por uma linguagem prestes a desmoronar, mantém afinidades com as características do teatro do absurdo. A leitura que o dramaturgo português apresenta do mito de Pigmalião na construção da sua peça evidencia a contradição do homem no confronto com as suas próprias aspirações, daí a inversão do mito. Por isso, o comportamento mítico do protagonista de $O$ colete de xadrez revela a contrariedade de uma certeza e a constatação da limitação humana.

\footnotetext{
${ }^{6}$ Segundo Berrettini (2004, p. 87, grifo da autora), o "termo Nada, usado num total de cinquenta vezes, e que abre a peça (...) coloca-a sob a marca do negativismo, embora haja a espera, frequente no refrão: "A gente espera Godot"'.
} 


\section{Revista do SELL}

v. $4, n^{\circ} .2$

ISSN: $1983-3873$

O diálogo dramatúrgico que Prista Monteiro estabelece com as peças de Molière e de Shaw diz respeito à alusão ao mito narrado por Ovídio, mas o que a peça de fato nos revela, através da leitura ou releitura desse mesmo mito, é o reconhecimento de que nem o comportamento mítico poderá livrar o homem de suas frustrações e do que é próprio da condição humana.

\section{Referências}

BERRETTINI, Célia. Samuel Beckett: escritor plural. São Paulo: Perspectiva, 2004.

CAMUS, Albert. O mito de Sísifo. Tradução de Ari Roitman e Paulina Watch. Rio de Janeiro / São Paulo: Record, 2004.

ELIADE, Mircea. Mito e realidade. Tradução de Pola Civelli. São Paulo: Perspectiva, 1972.

Arcádia, 1979.

Imagens e Símbolos. Tradução de Maria Adozinda Oliveira Soares. Lisboa:

ESSLIN, Martin. O teatro do absurdo. Tradução de Bárbara Heliodora. Rio de Janeiro: Zahar, 1968.

FADDA, Sebastiana. O teatro do absurdo em Portugal. Tradução de José Colaço Barreiros. Lisboa: Cosmos, 1998.

MOLIÈRE, Escola de mulheres. Tradução de Millôr Fernandes. São Paulo: Abril Cultural, 1980.

OVÍDIO. Metamorfoses. Tradução de Paulo Farmhouse Alberto. Lisboa: Cotovia, 2007.

PRISTA MONTEIRO, Helder. O colete de xadrez. In . O colete de xadrez; Folguedo do rei coxo. Lisboa: Arcádia, 1983.

SHAW, Bernard. Pigmalião. Tradução e adaptação de Miroel Silveira. In Santa Joana e Pigmalião. Rio de Janeiro: Delta, 1964. 